\title{
Certain ethno-medicinal plants of Sivasagar district, Assam and their uses
}

\section{MANJit Gogoi ANd P. JIJI}

\begin{abstract}
Ethno-medicinal plants play an important role in day to day life of rural people. Now-a-days Ayurveda gets more importance than allopathic medicines. Local inhabitants of Sivasagar district also give more attention in application of such medicinal plant resources which are available in different reserve forests, the district is one of the biodiversity rich hot spot of Assam. 11 per cent area of Sivasagar district is covered by reserve forests. During the study total 35 number of medicinal plant species were recorded with local name and uses. Moreover, it was informed that tribal and non-tribal peoples of the area maximum used plants belongs to family Zingiberaceae. Due to anthropogenic activities the forest is degrading slowly and a decline medicinal plant diversity. Therefore, conservation of this type of forests are essential for feature uses.
\end{abstract}

Key words : Medicinal plants, Anthropogenic activities, Conservation

How to cite this paper : Gogoi, Manjit and JiJi, P. (2015). Certain ethno-medicinal plants of Sivasagar district, Assam and their uses. Ann. Pharm. \& Pharm. Sci., 6 (1\&2) : 26-32.

Article chronicle : Received : 25.02.2014; Accepted : 23.09.2015 